\title{
¿Morirán mis hijos o las frutas del monte se secarán si no canto y uso mi amuleto cada noche? Mujeres tobas (qom) y Misioneros Anglicanos en el Chaco Centro occidental (Argentina)*
}

\author{
Mariana Daniela Gómez ${ }^{* *}$
}

\begin{abstract}
Resumen
En este artículo abordo cómo fueron observadas y representadas las mujeres tobas del oeste (qom) por los misioneros anglicanos de la South American Missionary Society (SAMS) durante su labor en la Misión El Toba, en el Chaco centro occidental, en la provincia de Formosa (Argentina). También analizo algunas actividades promovidas por la misión durante las décadas de 1930 y de 1940 que buscaban generar cambios culturales en los roles, en las identidades y en los espacios de las mujeres y los hombres. Veremos también la participación y las resistencias de las mujeres a estos cambios instituidos por la labor misionera.
\end{abstract}

Palabras clave: Misioneros Anglicanos, Mujeres Tobas, Género, Chaco Argentino

\footnotetext{
* Recebido para publicação em junho de 2010, aceito em fevereiro de 2011.

** Becaria Doctoral del CONICET (Consejo Nacional de Investigaciones Científicas y Técnicas), Argentina. Instituto de Ciencias Antropológicas. Sección Etnología y Etnografía. Facultad de Filosofía y Letras. Universidad de Buenos Aires.gomin19@yahoo.com
}

cadernos pagu (36), janeiro-junho de 2011:187-222. 
¿Morirán mis hijos o las frutas del monte se secarán si no canto y uso mi amuleto cada noche?

Will my Children Die or the Fruit from the Bush Dry up if I Don't Sing or Use my Amulet Every Night? Toba Women and Anglican Missionaries in Mid-Western Chaco (Argentina) in the 1930's and 1940's

\begin{abstract}
In this article I approach how were observed and represented Toba women by the Anglican missionaries from the South American Missionary Society (SAMS) during their work at Misión El toba, on the West-Center Chaco, Formosa province (Argentina). I analyze too some activities promoted by the mission back in the 1930's and 1940's which seemed to generate cultural changes on the roles, identities and on women and man spaces. We'll also see the participation and the resistances of women to these imposed changes by the missionary work.
\end{abstract}

Key Words: Anglican Missionaries, Toba women, Gender, Argentinean Chaco. 
Mariana Daniela Gómez

\section{Tobas y misioneros anglicanos en el Pilcomayo en las primeras décadas del siglo $\mathrm{XX}$}

Desde el año 2002 en adelante he trabajado en proyectos de gestión, desarrollo e investigación en comunidades indígenas tobas $(q o m)^{1}$ del oeste de la provincia de Formosa, Argentina. En el marco de mi beca doctoral desde el año 2006 investigo la construcción social y la dinámica histórica de las relaciones de género entre los tobas. ${ }^{2}$ Estoy particularmente interesada en las transformaciones en la construcción cultural del género femenino desde 1930 en adelante, considerando un contexto histórico marcado por la transición de los grupos tobas desde un modo de vida semi-nómada o transhumante (cazador-recolector-pescador) hacia una vida sedentaria, teniendo en cuenta diversos procesos paralelos como la incorporación laboral de los tobas en los ingenios azucareros del noroeste del país desde fines del siglo XIX, la pérdida de los territorios tradicionales de caza y recolección ante el avance de los nuevos colonos, el proceso de conversión religiosa llevado adelante por los misioneros anglicanos $y$ posteriormente, la creciente interrelación de los indígenas con nuevas instituciones y representantes del estado y de la sociedad nacional.

En la actualidad los tobas están asentados en una propiedad que poseen a título comunitario y que abarca unas 35.000 hectáreas en el departamento Bermejo, en el oeste de Formosa. Desde 1930 hasta 1980 aproximadamente convivieron con los

1 Los tobas del oeste, también conocidos como tobas-pilagá o tobas nachilamole\#k, representan una de las parcialidades tobas que actualmente habitan en diferentes provincias del territorio argentino (este de Salta, oeste y este de Formosa, Chaco y cordones urbanos de Santa Fé, Chaco y Buenos Aires). También existen parcialidades tobas en el chaco boliviano. El idioma que hablan pertenece a la familia lingüística guaycurú.

2 Utilizo el artículo plural masculino para referirme tanto a las mujeres como a los hombres tobas. 
¿Morirán mis hijos o las frutas del monte se secarán si no canto y uso mi amuleto cada noche?

misioneros anglicanos de la South American Missionary Society $(\mathrm{SAMS})^{3}$, sus principales interlocutores e intermediarios para lidiar con el resto de la sociedad argentina. La política de conversión anglicana se organizaba alrededor de cuatro campos de acción: 1) la evangelización -considerada la labor más importante y a la que dedicaban más energía, recursos y tiempo, 2) la alfabetización de adultos y niños, 3) la atención de la salud, y 4) la inserción de los aborígenes en el "trabajo industrial" y en el trabajo de oficios (carpintería, artesanías, agricultura).

La presencia de los misioneros anglicanos en el Chaco centro-occidental se remonta al año 1910 cuando se establecieron en las instalaciones de los "Leach Brothers" a pedido de esta familia, propietaria de uno de los ingenios azucareros más importantes del país (La Esperanza) ubicado en San Pedro, Jujuy, que explotaba mano de obra indígena y criolla (De la cruz, 1989; Wright, 1983; Torres Fernández, 2006). Allí, los anglicanos fundaron su primera misión en territorio argentino, llamada Misión Los Urundeles. Los anglicanos venían estableciendo contactos y relaciones con la familia Leach desde 1898 y fue en el marco de esos acercamientos que se consolidó la idea de abrir una misión que los acercase a los indígenas que trabajaban allí (Torres Fernández, 2006). El proyecto de establecer misiones anglicanas a lo largo del río Pilcomayo en el Chaco argentino fue formulado originalmente por Barbrokke Grubb en 1892, quién tenía en mente la conformación de un "triángulo de misiones que uniera el Chaco paraguayo, argentino y boliviano" (id.ib.:56). Así, a este interés expansivo de la política anglicana se le unirá el de los empresarios del azúcar, quienes mediante la intervención de los misioneros buscaban controlar el consumo de bebida y las prácticas de violencia intertribal de los indígenas en el ingenio (Mendoza, 2004).

3 La South American Missionary Society fue una sociedad misionera de origen inglés, fundada por Allen Gardiner en 1844 con el nombre de Patagonian Missionary Society. Gardiner misionó en las islas Malvinas entre los nativos del sur de Argentina. 
En 1914 se fundó la Misión Algarrobal entre los wichi (mataco) en el Chaco salteño, convirtiéndose en la misión central en territorio argentino. ${ }^{4}$ A partir de 1928 distintas delegaciones encabezadas por destacados líderes tobas (jaliaganeq) comenzaron a acercarse a la misión de San Andrés (fundada en 1927), pidiendo insistentemente que los anglicanos abriesen una misión en su propio territorio (Hunt, 1928; Smith, 1929a, 1929b). Para ese entonces, los tobas atravesaban una difícil situación de arrinconamiento militar, conflictos armados con los gendarmes y pobladores criollos, a lo que se sumaba la gradual pérdida de acceso a sitios de su territorio tradicional. En respuesta a este pedido, en 1930 los anglicanos fundaron la Misión el Toba, a orillas del Pilcomayo en su cuenca media, bajo la responsabilidad del misionero Alfred Leake, quién permanecería allí - junto a su familia-por más de dos décadas.

No es el objetivo de este trabajo analizar los aspectos centrales de la política misionera anglicana en el Gran Chaco (ver Torres Fernández, 2006, 2007; Gordillo, 2004). Sólo diremos que si bien seguía los lineamientos del discurso oficial sobre la "integración" y la "asimilación" del indígena al estado-nación argentino, no podríamos afirmar que los misioneros se encontraban en el Chaco sólo con el fin de "disciplinar" mano de obra indígena para ponerla a disposición de los ingenios azucareros. Un argumento de este tipo pasaría por alto la complejidad, la ambivalencia y la contradicción que se leen en los informes de los anglicanos, así como la lógica moral, social y

${ }^{4}$ En 1926 se abrió una misión en el Chaco Boliviano, en el Izozo (Aquaragua Izozog), a cargo del pastor Panter, pero durante la Guerra del Chaco debió permanecer cerrada. Cronológicamente le siguió Misión San Andrés (1927) a cargo de B. Grubb, quien además era el Superintendente de la Misión Argentina en el Chaco. En 1930 comenzó a funcionar la misión El toba y en 1933 se fundó San Patricio entre grupos wichis ("matacos del este", según los anglicanos). En 1935 se abrió la Misión Pilagá, una experiencia efímera que vio su fin en 1939 cuando, luego de varios conflictos interétnicos los pilagás - renuentes a sedentarizarse - la abandonaron. Le siguieron finalmente Misión El Yuto (1936), Pozo Yacaré (1938) en el Bermejo y en 1944 Misión La paz (Salta). 
¿Morirán mis hijos o las frutas del monte se secarán si no canto y uso mi amuleto cada noche?

religiosa bajo la cual emprendían su trabajo en la región. La utilidad que buscaban eran más bien religiosa antes que económica, puesto que deseaban orientar a los indígenas hacia una nueva forma de vida que no necesariamente estaba representada en la imagen de los indígenas trabajando en el ingenio o en la fábrica. Las misiones anglicanas representaban un tipo de "formación de poder" intermedia entre el "poder pastoral" (Foucault, 2006) y el "poder disciplinario (Foucault, 2008). Las políticas misioneras ciertamente podían ser funcionales al discurso y a los intereses de distintos sectores hegemónicos, pero lo cierto es que los diversos actores que confluyeron para esa época en el Chaco centro-occidental concentraban objetivos distintos (Lagos, 2000; Gómez, 2009a).

Como señala Torres Fernández (2007:137), en el marco de una coyuntura nacional donde se discutía el "problema indígena", el proyecto misionero de los anglicanos apuntaba hacia la integración, la civilización y la conversión de los indígenas chaqueños pero preservando simultáneamente ciertos rasgos culturales (los que se consideraban productivos para construir una nueva comunidad religiosa indígena). El objetivo principal de este proyecto pasaba por la conformación de una "Iglesia Nativa Protestante" de base pan-indígena (id.ib.:142). Ello explica la importancia que los anglicanos dieron a la incorporación de los nativos (hombres) a la estructura de cargos eclesiásticos y a la participación de los indígenas en diversas funciones de la misión, tanto en las misiones de Argentina como en las de Chile (Chávez y Avendaño, 2006).

Los anglicanos, aun operando dentro de relaciones de clara raigambre colonialista y desde los esquemas integracionistas de principios del siglo $\mathrm{XX}$, en varias oportunidades mostraron una posición crítica respecto a los ingenios, denunciando la explotación, la muerte y las epidemias que sufrían los indígenas (Leake, 1943:12, 1948:63; Tebboth, 1943:36; Fox, 1958:24). No obstante, es cierto que los misioneros veían con malos ojos a la zafra ya que allí -y fuera del control de la misión- los indígenas 
retomaban las prácticas que habían sido prohibidas por inmorales y satánicas (danzas, bebidas, cantos y curaciones chamánicas) (Gordillo, 2004; Tebboth, 1942).

La institucionalización de nuevos espacios de socialización, la censura de ciertas performances y actividades que eran parte de la praxis cotidiana de los tobas y la producción de dispositivos para controlar y/o erradicar comportamientos y modos corporales que comportaban "salvajismo", son tres ejes que se mencionan en la mayoría de los textos de todos los misioneros ${ }^{5}$ que trabajaron o pasaron fugazmente por la Misión El toba. Así, espacios, cuerpos y prácticas son tres dimensiones que se dibujan tensamente cuando son referidas de manera contrastante entre los indígenas y los blancos -en este caso "blancos" de origen inglés-, poniendo de relieve las tensiones desplegadas en la convivencia de un ser genérico considerado salvaje o bárbaro (inferior) y un ser considerado civilizado (superior) y de origen europeo. De este modo, las ecuaciones simbólicas en torno a los binomios civilización/barbarie y paganismo/cristianismo ordenaron la experiencia de los misioneros que acompañaron a los tobas durante las primeras décadas del siglo XX. Posteriormente, con el paso de las décadas y los cambios devenidos en los discursos gubernamentales oficiales y científicos respecto a la situación de los indígenas o al "problema del aborigen", el discurso misionero también se fue modificando.

A continuación voy a presentar un análisis en torno a tres ejes que se interrelacionaron en el proceso de conversión y civilización en la Misión El toba: 1) cómo fueron observadas y representadas las mujeres tobas por los misioneros y qué aspectos de ellas se resaltaron; 2) las modificaciones impulsadas por los misioneros en las dimensiones espaciales, corporales e identitarias involucradas en la estructuración social del género en los asentamientos tobas; 3) las expresiones de resistencia de las

5 Utilizo el artículo plural masculino para referirme tanto a los misioneros como a las misioneras, a menos que lo aclare explícitamente. 
¿Morirán mis hijos o las frutas del monte se secarán si no canto y uso mi amuleto cada noche?

mujeres a la política anglicana. Estos dos últimos ejes se abordarán conjuntamente en el tercer apartado.

\section{Guerreras y tímidas doncellas del Pilcomayo}

Las observaciones sobre las mujeres indígenas del Gran Chaco que aparecen en los relatos de los misioneros, exploradores y etnólogos de la región desde el siglo XVIII en adelante, se vinculan a tres imágenes estereotipadas que se construyeron para describir su situación: bestias de carga, amazonas o guerreras y libertinas sexuales (Gómez, 2010, 2011). Así, cuando las indígenas estuvieron bajo las lupas masculinas emergieron imágenes cinceladas por el racismo, el etnocentrismo, la exotización y, algunas pocas veces, el romanticismo. Este es el caso del inspector del gobierno argentino, José Niklison, quien en sus informes de la segunda década del siglo XX, demostraba su admiración ante la fortaleza física de las mujeres tobas y simpatía hacia sus expresiones de afecto, amor y celos, buscando contrarrestar los comentarios de otros hombres que ofrecían una mirada netamente racista y peyorativa sobre las indígenas, refiriéndose a ellas como "repugnantes monstruos de fealdad" o "bestias de carga" (Niklison, 1990:60). ${ }^{6}$

La mirada de los misioneros no corresponde directamente a este discurso negativo pero sus escasas observaciones sobre las mujeres - en particular las elaboradas por las misioneras - no escapan a los términos racistas y etnocentristas. Las mujeres tobas sorprenden cuando son contrastadas con las características del mundo femenino urbano, occidental y pequeño-burgués de las

6 "La mujer, considerada según el criterio de los hombres civilizados, viene a ser un animal de trabajo, una bestia de carga en los hogares tobas, pero son queridas por sus compañeros y ejercen evidentemente una influencia tenaz y decisiva en el ánimo y en los actos de los hombres" (Niklison, 1990:59). La idea de que las mujeres indígenas eran unas "bestias de carga" o "esclavas" de sus esposos fue una imagen recurrente y no fue privativa del Gran Chaco (Storm, 1892; Fontana, 1977), puesto que apareció en los reportes de los exploradores de otras regiones del mundo (Harbin y Kan, 1996; Brangdon, 1996). 
primeras décadas del siglo XX. Dora Tebboth, misionera y esposa del misionero y lingüista Thomas Tebboth, se refirió en varias oportunidades a la timidez y la indiferencia que según ella caracterizaba a las tobas. Su moral de clase media británica y protestante, sus modales urbanos y todo su habitus femenino se escandalizaban ante la "falta de moral", de "higiene personal" y esa actitud de "descuido ante los hijos" que las tobas pavoneaban en la misión. No eran mujeres limpias ni madres que supieran disciplinar y criar adecuadamente a sus hijos: en ellas residía el germen del salvajismo.

En general, en los informes misioneros ${ }^{7}$ no abundan las referencias a las mujeres tobas y cuando son mencionadas suelen ser tratadas como un colectivo serial: se habla de "las mujeres" y que "hacen esto" o "no hacen aquello". Esto se debe a que en los documentos anglicanos hay un doble sesgo masculino: a la hora de observar la vida indígena, los hombres tobas son los protagonistas, y quienes generalmente escribían sobre ella eran los hombres misioneros, aun cuando en la Misión El toba trabajaron cinco mujeres ${ }^{8}$ en diferentes momentos desempeñándose en las áreas de educación y salud. Pero eran los hombres quienes generalmente se encargaban - hay algunas excepciones - de

7 Publicados en el órgano de prensa titulado South American Missionary Society Magazine.

8 Olivia Leake, la hermana de Alfred Leake, trabajó en la misión desde que se instaló junto a su hermano, en 1930, hasta 1937 cuando regresó a Inglaterra para cuidar a sus padres. Olivia se desempeñaba como maestra en las escuelas de niños y mujeres y también como enfermera, recorriendo las comunidades en bicicleta. Fue la primera misionera anglicana a trabajar en el Gran Chaco. También trabajaron como maestras y organizadoras de los cultos de mujeres Dora Tebboth, esposa de Tomás Tebboth; la señora Leake, esposa de Alfred; la maestra Bárbara Kitchen, quién permaneció en la misión cerca de tres años y escribió varios reportes informando sobre la situación de las escuelas misioneras hacia fines de la década del 1950; y Ms. Bradberry, quien arribaría a la misión junto a su esposo en julio de 1957. Los anglicanos aceptaban mujeres en sus filas misioneras pero los roles más importantes en la estructura clerical eran ocupados por hombres. 
¿Morirán mis hijos o las frutas del monte se secarán si no canto y uso mi amuleto cada noche?

redactar los reportes trimestrales describiendo los "avances" y "retrocesos" del proceso de conversión religiosa de los tobas.

Al igual que en otras misiones religiosas del mundo (Notarianni, 1996), los misioneros anglicanos tendieron a enfatizar las relaciones con los hombres indígenas en detrimento de las mujeres, trayendo consigo y poniendo en práctica la ideología de género de ciertos sectores sociales europeos patriarcales y cristianos. Al parecer, las mujeres tobas fueron un sujeto marginal para la perspectiva y la labor misionera. Cuestión paradójica, si pensamos que las mujeres tobas en la actualidad se definen de maneras afirmativas respecto a la importancia que la "religión", el "evangelio" y "Dios" tienen en sus vidas.

Tres elementos del mundo femenino toba inquietaron $y$ asombraron a los misioneros: la timidez, la fuerza corporal y las peleas de mujeres. Los movimientos corporales lentos, la negativa de niñas y jóvenes a contestar las preguntas de la maestra en las clases escolares, la indiferencia expresada por las adultas y ancianas hacia la presencia misionera, su escasa asistencia a los cultos, la fuerza que invertían en sus tareas domésticas y las peleas de mujeres ocasionadas por los "robos de maridos", llevaron a que los misioneros se refirieran a ellas de maneras contradictorias. Por momentos, eran las "tímidas doncellas del Pilcomayo" a quienes les costaba demasiado avanzar en las lecciones de la escuela (Leake, 1933:6). En otras oportunidades fueron retratadas como unas "amazonas enojadas" (id.ib.:113) que se calzaban brazaletes y muñequeras adornadas con espinas con el fin de golpear y lastimar a sus adversarias de lucha:

Deberías escuchar a dos mujeres tobas teniendo una pelea. Se gritan una a la otra durante horas, utilizando el lenguaje más vil que ninguna persona decente podría usar. Sólo los que son parientes pueden unirse y estar tranquilos (...) especialmente los hombres no toman parte en el asunto, pero luego del evento cualquier hija de la mujer concerniente odia a la otra por disputas lastimosas (Tebboth, 1989: 89). 


\section{Mariana Daniela Gómez}

Dos disturbios menores han sido causados por las peleas de las mujeres. Esta es una práctica de común ocurrencia entre ellas, debido, usualmente, a problemas matrimoniales (Leake, 1932).

La sangre corre en estas peleas, muñequeras y puños de hierro del más bárbaro tipo son usados por estas amazonas enojadas (Leake, 1933:69, resaltado nuestro).

Las peleas, la fuerza muscular que las mujeres tobas y pilagá ${ }^{9}$ desplegaban en el ámbito doméstico y en las tareas de recolección, perturbaban a los misioneros debido a que representaban una inversión de los estereotipos de género cristianos, basados en las cualidades físicas y morales de docilidad, sensibilidad, debilidad y sumisión femenina a la autoridad religiosa, paternal y marital. A principios de la década del 1930, cuando los misioneros estaban procurando instalarse en la Misión El Toba se mostraban atónitos frente a la ayuda que les ofrecían éstas mujeres, siendo ellas las que "de una manera que avergonzaría a más de un hombre" (Leake, 1931:52) levantaban y cargaban en sus hombros los sacos de harina y los pesados troncos para la construcción de las casas y depósitos de la misión.

El misionero Arnott, absorto, describía cómo las mujeres cruzaban el río para buscar grandes cantidades de leña y agua, remarcando que en las aldeas pilagá aquellos trabajos que

9 Los tobas del oeste y los pilagá del sureste asentados hoy en el oeste y centrooeste de la provincia de Formosa respectivamente, fueron tratados durante varias décadas como dos parcialidades tobas. Los misioneros se referían a los grupos pilagá que habitaban cerca del Estero Patiño como los "tobas del sur" ya que hablaban prácticamente el mismo idioma que los tobas de Sombrero Negro, tenían las mismas costumbres y mantenían relaciones amistosas entres sí. Métraux consideraba que los pilagá eran un subgrupo de los tobas y para referirse a ambos acuño el término "toba-pilagá". Pero lo cierto es que ambos grupos, los tobas y los pilagá, a pesar de reconocer sus semejanzas lingüísticas y haber vivido muy cerca en diversas ocasiones, se autoreconocen como dos grupos étnicos distintos. 
¿Morirán mis hijos o las frutas del monte se secarán si no canto y uso mi amuleto cada noche?

comprometían el uso de la fuerza física eran realizados por las mujeres y no, como se esperaría, por los hombres:

Cinco mujeres y un hombre fueron a buscar pasto para forraje un tiempo atrás. Los paquetes que las mujeres trajeron era colosales comparados con el del hombre. Remarqué la diferencia y el hombre dijo: 'iPero yo soy un hombre!' de una manera que hizo que mi percepción parezca sin sentido, un comentario ridículo. (...) iDeberían ver a las pequeñas niñas darles a los pequeños niños azotazos cuando creen que los necesitan! Kailogochigui me contó no hace mucho tiempo atrás: 'iMi mujer - ella me pega tan fuerte! Mirá mi boca. iElla es malvada!' (...) Muchas de las mujeres son más altas que los misioneros y con sus muñequeras de feroces espinas y metal, con sus rostros cubiertos desde la garganta hasta la frente de tatuajes, no son lo que nosotros hemos conocido como el "sexo limpio". Encontramos difícil acercarnos a ellas. Ellas son, después de todo, tímidas y son difíciles y diferentes (Arnott, 1938: 137).

Prácticamente toda la comida, excepto el pescado, es traída por las mujeres del monte de alrededor $\mathrm{y}$, a veces, ellas están fuera por días o por semanas. Esto probablemente se vincula a su amor por la vida nómade, muchas de ellas hallan muy difícil adaptarse a la rara y regular rutina de la vida de la misión (...) (Price 1937: 56).

A los misioneros también les llamaba la atención el hecho de varias llevaran el pelo corto (probablemente a causa de los rituales de duelo), mientras que los hombres lo usaran largo (Arnott, 1938; Price, 1937); también algunos informes señalan que eran ellas las que seducían y formulaban las propuestas de matrimonio a los hombres elegidos (Arnott, 1938). Esta representación sobre la vida sexual activa de las indígenas se vio reforzada en los escritos del antropólogo Alfred Métraux (1980) quién hizo investigaciones etnográficas entre los tobas y los pilagá en 1932-33 y luego en 1937. Allí él aseguraba que las tobas 
iniciaban las elecciones sexuales en el marco de las danzas colectivas nomi ${ }^{10}$ y en los encuentros festivos donde los tobas celebraran los rituales de iniciación femenina, hacían alianzas para la guerra, cantaban, bailaban y se emborrachaban con cerveza de algarroba (aloja).

Asimismo, los rostros tatuados, la vestimenta y ciertas actitudes estéticas de las mujeres y de los hombres fueron considerados contrarios a las expresiones estéticas occidentales $e$ inoportunos para el ejercicio de una correcta vida cristiana, encallada en el pudor y el recato. Hacia la década de 1940 la mayoría de los hombres utilizaba el cabello largo y suelto y, al igual que las mujeres, vestían unas largas piezas de tela coloridas (chiripa) amarradas a la cintura usando fajas de lana tejidas y teñidas con diversos colores (Gómez, 2009b). Cuando los hombres y las mujeres comenzaron a adquirir ropas modernas - como parte de su salario por el trabajo realizado en el ingenio -, podían usarlas $e$ intercambiarlas indiferentemente y "sin respetar su uso original", afirmaba el misionero Arnott (1932:43). Antiguamente (antes de ingresar en las misiones), la simbolización de la diferencia sexual de los indígenas chaqueños se corporizaba mediante tatuajes, perforaciones y escarificaciones y en menor

\footnotetext{
${ }^{10}$ Baile también conocido en el Gran Chaco como "baile sapo" o "baile del sapo". Se trataba de una danza donde los hombres bailaban en ronda rítmicamente, cruzándose tras los brazos y tomándose de la cintura al son de los repiqueteos de un tambor de agua tocado por un hombre que guiaba el ritmo. Según Citro (2009), en estas performances los hombres hacían gala de sus habilidades como danzantes y cantores delante de las mujeres. Las mujeres tenían un rol muy importante ya que también podían incorporarse a la rueda y danzar con los hombres o elegir y tocar por la espalda a los hombres que les gustaban como compañeros sexuales ocasionales. El nimí o nomí, asociado a la diversión, el canto y la sensualidad desplegada por los cuerpos danzantes, antiguamente se bailaba en el monte y era en el marco de estas fiestas donde se bebía la cerveza de algarroba que luego sería prohibida por los misioneros en varios asentamientos. El nomí se trasladó al espacio de los ingenios y a otros contextos laborales (Gordillo, 2004; Citro, 2009).
} 
¿Morirán mis hijos o las frutas del monte se secarán si no canto y uso mi amuleto cada noche?

medida a través de las escasas prendas que se fabricaban con cuero y chaguar (Bromelia hieronymi y Bromelia serra). ${ }^{11}$

Más allá de estas cuestiones, el aspecto que más inquietaba a los misioneros era la timidez y la distancia verbal, espacial y corporal que las mujeres procuraron mantener con ellos. La "mujer toba" era una presencia huidiza, difícil de representar y de tratar:

Su comportamiento es tan extraño para estas mujeres tobas, quienes usualmente son tímidas y tontas y uno raramente puede obtener alguna explicación de ellas (Tebboth, 1943:37).

Las mujeres no son tan atractivas como los hombres o los niños, y son mucho más difíciles de entender. Parecen preocuparse poco por la vestimenta con la excepción de unas pocas jóvenes aquí y allí. Sus rostros, no obstante, están tatuados con todo tipo de maravillosos diseños. Es su costumbre llevar el cabello corto, mientras que los hombres lo llevan largo (...) (Price, 1937:56).

Esta visión coincide con lo que han señalado varios autores que han investigado las respuestas de las mujeres nativas de Norteamérica a la avanzada del cristianismo en sus aldeas: las mujeres indígenas fueron vistas por los misioneros menonitas, pentecostales y católicos como los miembros más conservadores de sus grupos, las más renuentes a modificar sus formas de vida y el lazo débil en el proceso de conversión, mientras que los hombres indígenas se mostraron más inclinados a aceptar las nuevas oportunidades económicas y los roles sociales ofrecidos o

${ }^{11}$ En la actualidad las mujeres tobas tienen una forma de vestirse $y$ adornarse (polleras de colores largas hasta los tobillos, remeras, zapatillas, pañuelos para la cabeza) que denota la apropiación de la moral sexual femenina cristiana, puesto que su presentación estética enfatiza el ocultamiento de las piernas y los senos así como el uso del cabello largo. Los hombres suelen invertir más dinero para vestirse de manera "moderna" y utilizan vaqueros o jeans, camisas, zapatos, zapatillas, botas de cuero y el cabello corto (Gómez, 2009b). 
impuestos (Harbin y Kan, 1996). Los misioneros anglicanos del Chaco parecen haber concebido de igual modo a las mujeres tobas.

Sin embargo, en la Misión El toba, a pesar de que las mujeres eran un sujeto de interés menor en el programa de conversión, se esperaba de ellas que abandonasen sus rituales de duelo y de iniciación femenina (con la llegada de la menarca, estado denominado ne'tagae), sus danzas y cantos, las actitudes conyugales tenidas por indecentes (contraer matrimonio con hombres más jóvenes que ellas, adulterio) y las peleas que mantenían entre sí, expresiones de "violencia" consideradas por los misioneros como un epónimo del grado de salvajismo e inferioridad moral en el que todavía, en pleno siglo XX, estaban sumergidos los tobas. A cambio de estas renuncias, los misioneros les ofrecían la posibilidad de alfabetizarse en la escuela de mujeres, de convertirse en "respetables cristianas", en "madres responsables" y orientarlas en el "trabajo industrial", mediante la compra y venta de sus artesanías. La actuación de los misioneros en esta esfera reforzará una concepción sobre el trabajo femenino que ya pertenecía a los grupos tobas: una mujer trabajadora o guapa (uañagae) era aquella que sabía tejer y vincularse con el monte y sus recursos o, en otras palabras, con el "conocimiento práctico" (Bourdieu, 1991) propio de las prácticas de recolección femenina (Gómez, 2008).

El proceso de misionalización entre los tobas puso en marcha de manera conjunta, una serie de cambios operados sobre los cuerpos, las identidades y los espacios de las mujeres y los hombres. Influenciados por su propia ideología de género, los misioneros entendían que el mundo femenino y el masculino debían funcionar de forma segregada y en tiempos distintos. Además, mientras que a los hombres se les exigió abandonar performances centrales en la conformación del "ethos masculino" del indígena chaqueño (como el chamanismo por ejemplo), a las mujeres se las exhortó a replegar del espacio público sus comportamientos "salvajes", ya que se pretendía feminizarlas y 
¿Morirán mis hijos o las frutas del monte se secarán si no canto y uso mi amuleto cada noche?

domesticarlas, de acuerdo con los rigores de la vida maternal y del cristianismo.
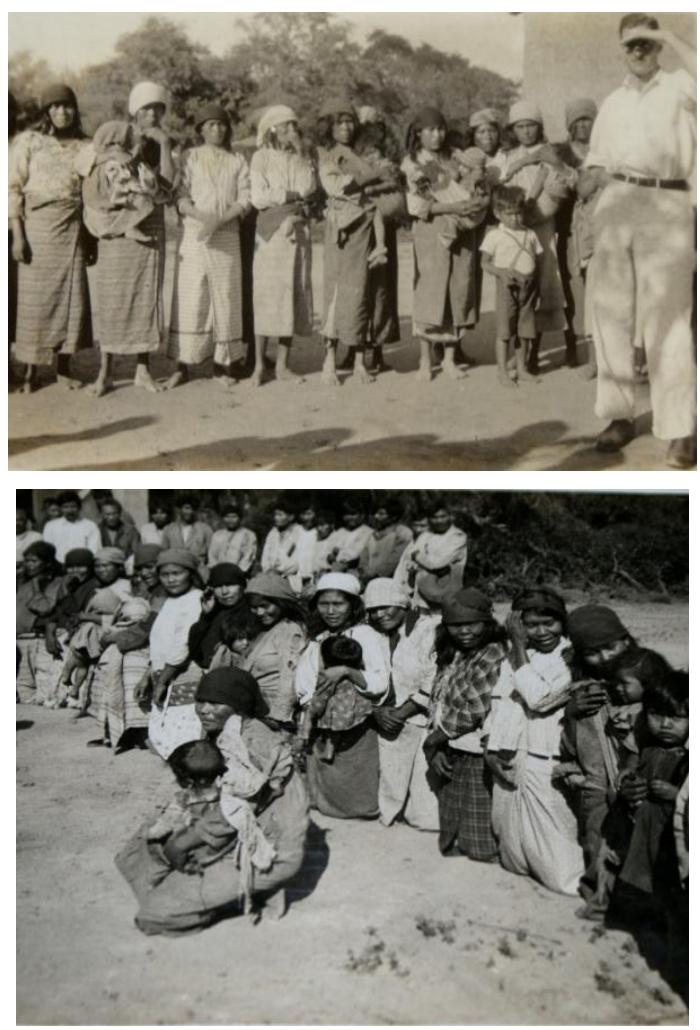

Mujeres con sus niños en alguna de las misiones anglicanas del Chaco centro-occidental, posiblemente Misión San Patricio, Salta. ${ }^{12}$

12 Todas las fotos que aparecen en este trabajo se encuentran en el Archivo de la Catedral Anglicana de Buenos Aires. Agradezco a la fotógrafa María Noel Puebla quién ha estado a cargo de tomar las fotos y mejorar su calidad visual para esta presentación. 
Mariana Daniela Gómez

\section{Civilizando a las mujeres: transformación de espacios, hábitos y roles}

La política misional hacia las mujeres se orientó a configurar nuevos comportamientos, roles y hábitos civilizados, a través de la intervención en la vestimenta femenina, en la higiene personal, en el trabajo artesanal y en las pautas de crianza e higiene de sus hijos. En este sentido, las transformaciones impulsadas se proponían la alfabetización, cristianización y maternización de las mujeres. Los espacios para llevar adelante estos cambios fueron las escuelas de niñas y mujeres, los cultos y reuniones de rezo femeninas, y las campañas de higiene y vacunación llevadas adelante en el dispensario sanitario de la misión.

Sin embargo, en el marco de la política misional las mujeres tobas quedaron marginadas de los nuevos roles de liderazgo religioso que los misioneros crearon para los antiguos líderes y chamanes (piogonaq) que se iban convirtiendo a la nueva religión. Por otra parte, los trabajos pagos que se podían realizar en la misión (carpintería, construcción, mensajería) solían ofrecerse a los hombres, aunque entre las mujeres se promovía la producción de artesanías que los misioneros luego compraban y revendían en su propio almacén o a otros comerciantes que andaban por la zona. ${ }^{13}$ Sólo ciertas jóvenes predilectas fueron seleccionadas para trabajar en las casas de los misioneros como ayudantes domésticas, en las tareas de cocina, costura, lavado y planchado de ropa.

El trabajo doméstico y la relación con las "criadas" propiciaban un contacto más íntimo entre las misioneras y las jóvenes tobas, y la sorpresa por parte de las primeras ante ciertas cualidades positivas que descubrían en ellas que pasaban desapercibidas en otros espacios. Al encontrarse en un contexto que estaba por fuera de las tensiones y expectativas impuestas en la escuela o los cultos, este tipo de relación posibilitaba otro tipo

13 "Las tobas todavía hacen sus artesanías y estoy orgullosa de eso porque es una pena cuando las tribus nativas se vuelven tan civilizadas que abandonan sus artesanías" (Tebboth, 1989:140). 
¿Morirán mis hijos o las frutas del monte se secarán si no canto y uso mi amuleto cada noche?

de encuentro entre éstas mujeres de diversos orígenes y edades. No obstante, en las descripciones de las misioneras se advierte que con el establecimiento de este tipo de relaciones buscaban entrenar a las jóvenes en el régimen doméstico y observar sus aptitudes con mayor detenimiento. Y, muy a pesar de que el trabajo doméstico de las tobas en sus hogares por momentos se presentaba como un reflejo especular de las cargas domésticas que enfrentaban las misioneras en sus propios hogares, no dejaron de posicionar a sus "criadas" en una relación laboral que asumía características serviles y coloniales.

Este tipo de abuso de la joven indígena como criada doméstica iba en contra del discurso humanista que los misioneros (hombres) resaltaban en sus informes cuando criticaban, por ejemplo, las relaciones de explotación que padecían los indígenas en los ingenios azucareros. Al interior de la misión, las relaciones establecidas entre las jóvenes tobas y las misioneras inglesas mostraban ribetes que anudaban prejuicios racistas, clasistas y sexistas:

Mi criada Yagalena es una chica brillante pero no para ser confundida con una chica blanca. Tiene una mente simple de india y ella nunca ha tenido la posibilidad de ver las cosas buenas. Todo lo que ella sabe y puede hacer es lo que ha aprendido de su tribu y de la misión. Adora hurgar en mis cosas y mirar mis fotos y revistas cuando aparentemente no estoy mirando. Intentaré fotografiarla algún día. Se podría ver muy bonita (Tebboth, 1989:110).

Rompimos relaciones [con Yagalena] porque ella se negó a hacer lo que le decía, puso mala cara y luego le dije que se vaya (ella es la clase de persona que disfruta siendo asquerosa con cualquiera). Decidí no reconsiderarla hasta que no se haya convertido. Esa posibilidad parece remota para mi desconfiada ment (id.ib.:161). 
Mariana Daniela Gómez

\subsection{Segregación sexual del espacio}

Antes de la llegada de los misioneros los tobas vivían agrupados en bandas ${ }^{14}$ y la vida cotidiana de una familia extensa estaba expuesta a la presencia de las otras. Cuando los tobas no migraban al ingenio, la vida transcurría entre los asentamientos estables (sitios cercanos al río, a las lagunas y a los madrejones) y los campamentos temporarios en el monte, hacia los cuales se movilizaban familias enteras o grupos de hombres o mujeres adultos para cazar o recolectar. En suma, la configuración espacial de los asentamientos era muy distinta a la que posteriormente impondrá la misión, si consideramos que anteriormente el espacio no estaba dividido sexualmente y que tanto los hombres como las mujeres practicaban una alta movilidad para la búsqueda de recursos. ${ }^{15}$

\footnotetext{
${ }^{14} \mathrm{La}$ banda en el pasado representaba la unidad social mínima y estaba conformada por un grupo de familias extensas unidas por lazos de parentesco, que recorrían juntas un mismo territorio a lo largo del ciclo anual. Varios grupos indígenas del Chaco estaban organizados de esta manera. Las bandas confluían en distintas épocas del año para celebrar alianzas, rituales, danzar y beber cerveza de algarroba. Para profundizar la aplicación del concepto de banda al Gran Chaco ver Braunstein (1983).

${ }^{15}$ Varias fuentes y autores señalan que las mujeres se movilizaban más que sus compañeros y que si bien compartían el espacio del hogar donde se hacían diversas tareas domésticas, se advierte que el trabajo doméstico de las mujeres incluía una cantidad mayor de actividades, de inversión de tiempo y de esfuerzo. Por otra parte no existía una segregación sexual espacial pero, la espacialización del género y del sexo existía y mostraba sus efectos. La violencia y las venganzas entre grupos étnicos solían descargarse en los cuerpos femeninos del grupo rival y las mujeres, al salir al monte a recolectar podían ser tomadas como cautivas junto con sus niñas y niños, ser agredidas sexualmente o muertas. También es cierto que no existía una división entre un espacio doméstico feminizado en contraste a un espacio público y masculino, pero la organización de la vida cotidiana y del trabajo asignaba con exclusividad a los hombres una esfera de actividades que implicaban un rango de acción por fuera de la estructura familiar, algo que las mujeres parecen no haber compartido con ellos. El liderazgo, la guerra interétnica para mantener el dominio territorial y el chamanismo son los ejemplos más contundentes de los espacios de poder masculinizados.
} 
¿Morirán mis hijos o las frutas del monte se secarán si no canto y uso mi amuleto cada noche?

Desde sus orígenes, la misión anglicana se constituyó como un lugar extraño y ajeno a las prácticas cotidianas de los tobas. Sin embargo, poco a poco, muchas familias se aglutinaron en este lugar puesto que allí se aseguraban un relativo acceso a las mercaderías, servicios y trabajos que los misioneros distribuían. La lógica de acción misionera deseaba delimitar espacios, jerarquizarlos, instituir reglas de comportamiento a seguir en cada uno de ellos (especialmente en las escuelas y en la iglesia). De este modo, se buscaba civilizar los cuerpos femeninos y masculinos, sus modos corporales, sus expresiones y hasta su decoración y vestimenta, de acuerdo al espacio en el que se estaba. Así, se crearon nuevos espacios (casas de los misioneros, depósitos, dispensario, carpintería, baños, escuelas, iglesia) a los cuales los tobas tenían un acceso limitado según horarios y pautas correctas de comportamiento y aspecto, y una circulación por los mismos de acuerdo al género, es decir: una nueva espacialidad signada en términos de pertenecer a un sexo $\mathrm{u}$ a otro.

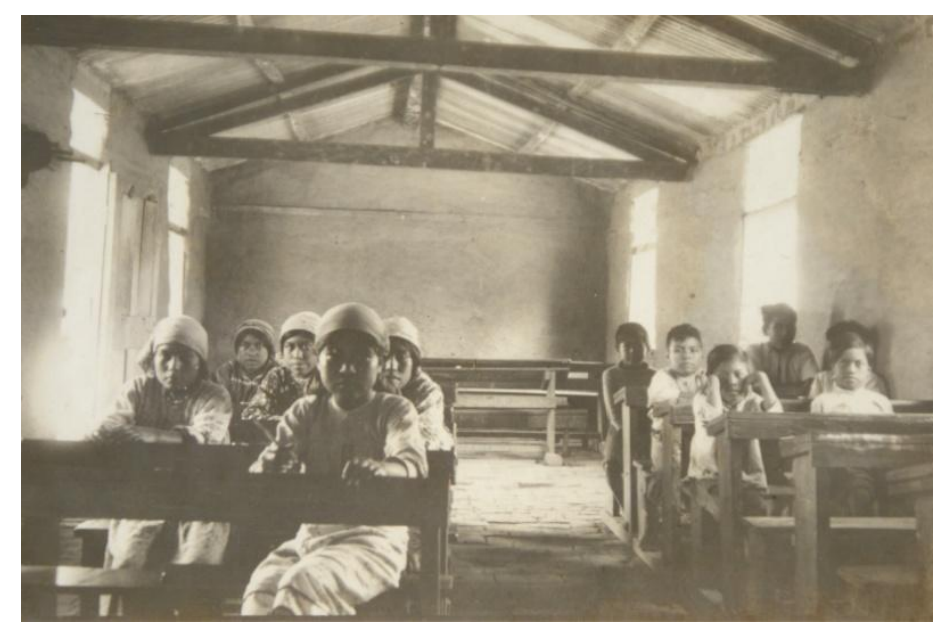

Sin embargo, los informes muestran que esta política no tuvo un gran impacto durante los primeros años de la misión y no 
lograba traspasar los espacios delimitados para desarrollar las tareas misionales. Los informes de los misioneros señalan que en sus casas los tobas burlaban los preceptos de la moral cristiana y continuaban bebiendo la cerveza de algarroba, se hacían curar por los chamanes, recibían compañeros o compañeras sexuales ocasionales y las mujeres continuaban atendiendo los rituales de iniciación femenina y de duelo y respetando una serie de tabúes.

Esto significa que el espacio de los hogares - exceptuando la introducción de algunos muebles fabricados por los hombres en la carpintería de la misión -, no fue objeto de escrutinio y control durante estas primeras décadas de presencia anglicana, a pesar de que sus condiciones materiales e higiénicas a las misioneras les resultaban intolerables. ${ }^{16}$ Los nuevos dispositivos de disciplinamiento, al parecer, sólo se establecieron en los espacios inaugurados por la misión.

No obstante, la civilización de los cuerpos y de los espacios en el largo plazo mostrará sus marcas en las subjetividades tobas. Con el tiempo, los tobas internalizarán aquel discurso cristiano que castiga las faltas morales y la desviación respecto al patrón ideal de vida cristiana, basado en un código de conducta (no beber, no fumar, no mascar coca, no tener relaciones extraconyugales, condescendencia y amor para con el prójimo, no danzar, no cantar, no hacer los rituales), que fue cercenando y reprimiendo las expresiones típicas del habitus indígena chaqueño.

\footnotetext{
${ }^{16}$ Si bien en la actualidad las casas de los tobas están hechas comúnmente con ladrillos de adobe, techos de chapa, ramas y hojas y una familia extensa cuenta con varias habitaciones aunque no necesariamente conectadas entre sí, hacia la década del 1940 y parte de la de 1950 los tobas vivían en casas de aspecto más precario o "tradicional". Hay que considerar que para ese entonces los tobas aun se movían bastante para buscar alimentos, estaban fuera de la misión durante ocho meses trabajando en los ingenios y no existían planes de vivienda impulsados por los misioneros. Probablemente esto se deba a la falta de financiamiento para iniciar transformaciones de este tipo, a la amenaza de las inundaciones que se recrudecieron a partir de 1944 y al hecho de que la misión estaba emplazada en una zona ribereña y rural, alejada de los centros agroindustriales.
} 
¿Morirán mis hijos o las frutas del monte se secarán si no canto y uso mi amuleto cada noche?

Sin embargo, me interesa plantear que gracias al sesgo ideológico de género que portaban los misioneros, las mujeres tobas sufrieron en menor medida los embates civilizadores. Las prácticas ferozmente combatidas fueron las que practicaban los hombres y aquellas vinculadas a la construcción de la masculinidad (el chamanismo por ejemplo). No hay evidencias en los informes de que los misioneros hayan reprimido - aunque sí desaprobado - los rituales de las mujeres, por ejemplo. Tales rituales se elaboraban en la periferia de los hogares, a menudo en chozas apartadas construidas para tal fin, debido a la polución y el peligro que condensan los fluidos de los cuerpos femeninos. "¿Qué me ocurrirá si no me recluyo?", se preguntaba una mujer que recientemente había enviudado. "¿Morirán mis hijos, o las frutas del monte se secarán si no canto y uso mi amuleto cada noche?". Así parafraseaban los misioneros las renuencias de las mujeres a abandonar sus rituales de duelo. En efecto, aparecen varias descripciones de estas reclusiones que debían practicar las viudas durante uno, y a veces dos años, tiempo durante el cual debían seguir una dieta liviana y rigurosa, cortarse el pelo y llevar unos amuletos en el cuello para evitar que los espíritus de sus maridos, nostálgicos de los goces de la vida terrestre, las molestasen.

La amenaza que contenían los cuerpos de las tobas al menstruar o ante la muerte de un familiar (marido o hijo), obligaban al distanciamiento y al aislamiento hacia los márgenes del hogar. En los informes tampoco aparecen referencias a las prácticas de infanticidio y aborto que las indígenas del Chaco (Métraux, 1980) practicaban sin comportar ningún tipo de represión moral, ya que según Métraux éstas prácticas, lejos de ser comportamientos ocasionales, desconocidos o poco comunes, ostentaban el rango de "institución social" (Métraux, 1948:426).

En suma, las dimensiones rituales de la vida femenina centrales en la construcción y simbolización del género- pasaron más desapercibidas para los misioneros, quienes se guiaban por sus preconceptos, por ejemplo, por la idea de que las tobas 
carecían de poder y autoridad en sus respectivos grupos. Sus rituales eran pequeños asuntos - incomprensibles para las misioneras inglesas - en comparación con las prácticas masculinas consideradas salvajísimas, tales como el chamanismo y las borracheras rituales. En otro sentido, además, el cuerpo de la mujer toba guardado, secreto, segregado y polutivo perturbaba a las misioneras porque en ello veían prácticas que menospreciaban y esclavizaban a las mujeres; pero también porque semejante peligrosidad, prudencia y obsesión ritual volcada en esos cuerpos y subjetividades - que las misioneras apenas alcanzaban a comprender- sobrepasaban en extremo sus propias ideas sobre el temor y el pudor del cuerpo femenino en el cristianismo.

En la cruzada misionera, la única práctica femenina que los misioneros intervinieron y lograron sino erradicar al menos invisibilizar en el espacio de la misión, fue la "pelea de mujeres". Como dije más arriba, estas peleas eran un epítome del salvajismo en tanto representaban la ausencia de control sobre las emociones, el despliegue público de la violencia física y verbal, además de tornarse un escenario donde la alteridad del mundo femenino se radicalizaba a tal extremo que se volvía indigerible para la lógica misionera. A diferencia de las guerras intertribales y de las leyendas sobre los audaces guerreros tobas, cuya violencia entronizaba la convicción y la valentía de "la raza" (masculina), la agresión física entre las mujeres fue considerada como un signo de inestabilidad social y atraso cultural.

\subsection{Escuelas y cultos}

Desde el comienzo de la misión se instituyeron escuelas segregadas por sexo y edad. Funcionaba una Escuela de Mujeres (Women School) que durante sus primeros años estuvo bajo la dirección de la misionera Olivia Leake; una Escuela de jóvenes y hombres adultos (Young men School) bajo el mando de su hermano Alfred Leake; y a partir de 1932 se abrió una Escuela para niños, la cual por momentos y dependiendo de la cantidad 
¿Morirán mis hijos o las frutas del monte se secarán si no canto y uso mi amuleto cada noche?

de alumnos se dividía en Escuela para niñas y en Escuela para niños. En estos espacios se impartían lecciones básicas de lectocomprensión y nociones de aritmética en toba y en castellano. Como parte de su modus operandi disciplinador, se apuntó a la construcción de un sentido de pertenencia nacional, mediante la conmemoración de las fiestas patrias y la incorporación de símbolos nacionales, como el himno nacional y la bandera (Torres Fernández, 2007).

Con excepción de los cultos masivos que se realizaban los sábados por la noche y los domingos al mediodía, el resto de los espacios religiosos donde se cantaba, se rezaba y se leían pasajes bíblicos y sermones también funcionaban sexual y etariamente diferenciados. Así, desde el principio de la misión se establecieron reuniones de rezo exclusivas para hombres, otras para mujeres y reuniones de rezo y canto de coros para los niños los sábados por la tarde. En 1939 se abrió una escuela para evangelistas (exclusiva para la formación religiosa de los hombres).

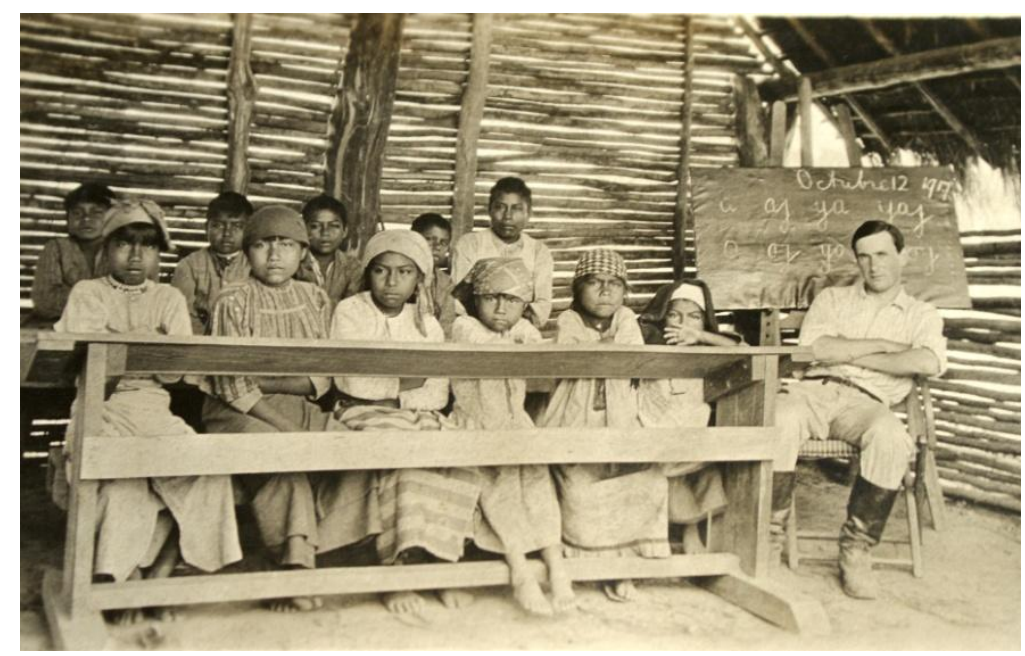

Una clase de niños/as, posiblemente en la Misión San Patricio, Salta. 
Las mujeres eran más reticentes a ingresar a la escuela y a participar en las "reuniones de rezo". Sencillamente no respondían a las convocatorias e invitaciones que las misioneras Olivia Leake o Dora Tebboth les ofrecían. En 1937 treinta y cinco alumnos asistían regularmente a la escuela mientras que a la Escuela de niñas sólo iban quince. Las mujeres adultas también asistían muy esporádicamente no sólo porque se resistían a hacerlo, también porque migraban junto a sus maridos al ingenio o se internaban en el monte para recolectar frutos, llevando a sus hijos consigo. En el verano, durante las expediciones de caza y recolección o en los meses de carestía en el invierno (principalmente en el mes de agosto), las escuelas eran temporalmente cerradas ya que muchas familias se marchaban al monte para buscar alimentos.

Frente a estas reticencias $e$ indiferencias las misioneras elaboraban otras estrategias: cambiaban el horario de las clases o improvisaban nuevos espacios de reunión y socialización, como las reuniones que Dora organizaba los lunes para las mujeres, invitándolas a tomar mate, a hilar y a tejer "artesanías" mientras ella les mostraba tarjetas con diversos motivos religiosos o narraba alguna historia vinculada al proceso de conversión o al evangelio:

Hoy tuvimos una buena reunión. Tengo una pila de tarjetas coloridas con aves de Sudamérica, peces y animales y varias tarjetas instructivas. Se las fui pasando a las mujeres para que las miren y para ayudarme a esclarecer el siguiente mensaje. Les hablé de la creación y enfaticé que había sido 'Dios' y les expliqué que las cosas creadas no tienen un 'espíritu' que los gobierna y que las criaturas de Dios no pueden ser brujeadas. Les mostré varias ilustraciones de las supersticiones tobas frente a las cuales las mujeres se rieron y dijeron que algunos creen que esas cosas existen. Un ejemplo que les di: 'Una mujer mayor, anciana y cristiana dice que su nieta está enferma porque la lechuza que duerme cerca de su choza ha brujeado a la niña durante la noche. Las mujeres lo creyeron. La niña murió de tuberculosis (Tebboth, 1989:132). 
¿Morirán mis hijos o las frutas del monte se secarán si no canto y uso mi amuleto cada noche?

Dora durante los primeros años de la década de 1940 (luego de la partida de Olivia Leake) también estuvo a cargo de la Escuela de niñas. Creía que las pequeñas y las jóvenes eran incapaces de concentración y carecían del deseo de aprender cosas nuevas (Tebboth, 1989) "....tenemos que enseñar primero el sentido de aprender antes de empezar a transmitir el conocimiento, y el primer paso es el más arduo" (id.ib.:86). Las clases se dictaban por la mañana y tenían una duración de dos horas. Para ella representaba un arduo trabajo lograr que las niñas se quedaran sentadas, respondieran a sus preguntas, fueran medianamente vestidas y no se entretuvieran o desconcentraran con los ruidos y las situaciones que ocurrían afuera de la clase.

Sus escritos de esos años reflejan la obsesión por el detalle, propia de los dispositivos disciplinarios de la educación cristiana y de la pedagogía escolar y militar (Foucault, 2008), aspectos que reproducían todos los misioneros cuando registraban las mínimas actitudes que auguraban un "mejoramiento", un "avance", un "retroceso" o un "estancamiento" en la actitud escolar de las niñas: si podían o no leer mejor, si podían o no distinguir "un seis de un tres" (Tebboth, 1989:85), si podían o no reproducir los himnos en español y en toba que ella les enseñaba, si se lavaban las manos y el rostro antes de ingresar a la clase, etc. La pedagogía de esta enseñanza consistía en la simple impartición de temas, la asimilación y la reproducción, en un espacio concebido para separar, individualizar, vigilar, marcar y jerarquizar a los individuos según sus aptitudes y capacidades. El consecuente "fracaso" de los niños, de los jóvenes y de los adultos de ambos géneros se atribuía a que "los indios" tenían "mentes simples", "mentes de niños" y "carecían de inteligencia". Además, como resultado del entorno primitivo en el que eran criados, las niñas y niños eran vistos como pequeños pecadores indiferentes, insolentes, indisciplinados y criados por madres descuidadas $y$ desatentas. A los ojos de Dora, muy lejos de la "inocencia" de los 
niños ingleses, los pequeños tobas estaban corrompidos desde su primera infancia.

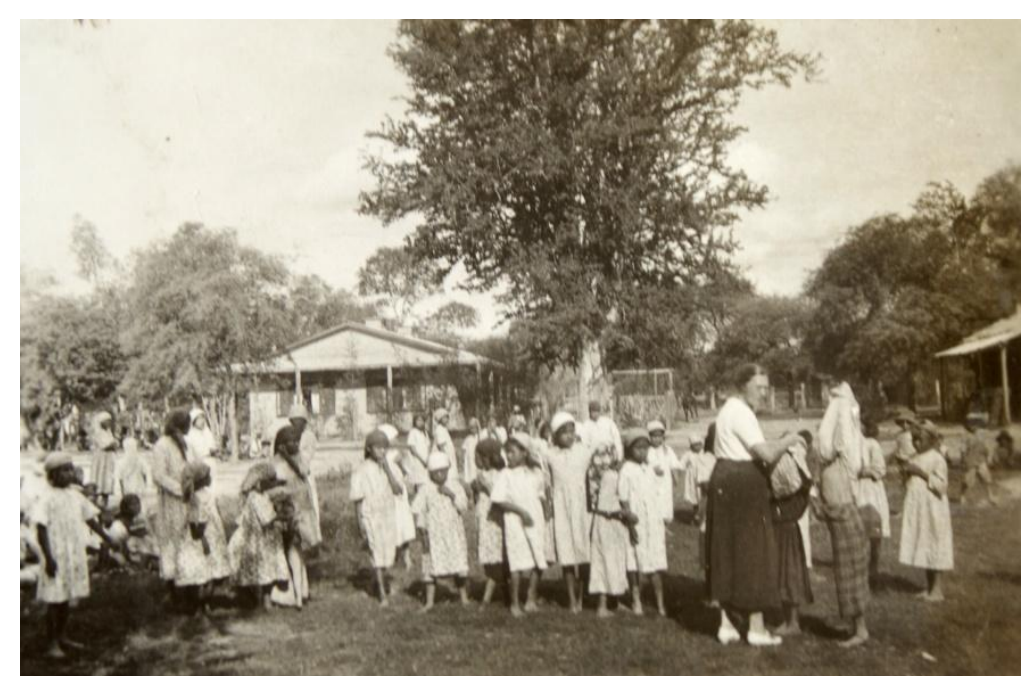

Misionera junto a las niñas de alguna misión del Pilcomayo (Misión San Patricio probablemente)

Por esta razón, mediante las escuelas las misioneras pretenderán introducirse en las pautas de crianza y socialización de los niños, terreno que hasta su llegada, estaba en manos de todas las mujeres que formaban parte de una familia extensa. Las críticas de las misioneras a las tobas en su rol de madres traslucen una concepción de la maternidad individualizada y burguesa, típica de la época pero totalmente ajena al contexto de los tobas, donde las faltas del niño son atribuidas exclusivamente a las imprudencias y descuidos de la figura materna. En este esquema, las mujeres tobas eran vistas como un caldo de cultivo para la indecencia e indisciplina de sus hijos, mientras que en su rol de esposas representaban un obstáculo en el proceso de conversión de sus maridos: 
¿Morirán mis hijos o las frutas del monte se secarán si no canto y uso mi amuleto cada noche?

Cuando regresemos de nuestras vacaciones pienso hacer más trabajo personal, afrontando a las libertinas, a las brujas y a otras. Reza por mí porque no será fácil. No es sólo que queremos ganarle a esta gente, queremos romper sus influencias sobre otros (Tebboth, 1989:136, resaltado nuestro).

Visitamos a una mujer en su aldea la semana pasada -se veía horrorosa-. Desafortunadamente la medicina no pudo ayudarla porque ella no estaba preparada para retener nada adentro suyo y entonces estaba marchita. La segunda mujer era la hermana de Isabel. Ella deliberadamente rechazó el evangelio y se dejó morir de hambre porque había sido brujeada. Actualmente sufría de un problema del corazón y se la hubiera podido dar atención pero ella pensó que Carancho el brujo ya la había brujeado y ieso es todo! Ella vio a otros brujos que eran enemigos de Carancho, combinando cánticos por las noches. Trató con todo menos con comida, medicina y rezos. Los maridos de ambas mujeres son cristianos, Onofre y Felipe y ambos prometieron mantenerse con fe. ¿Rezarías por ellos? (id.ib.:140).

Si la escuela de niñas representaba un espacio para docilizar a las mujeres durante su temprana infancia e introducir nuevos hábitos en la vestimenta, higiene y en la forma de hacer sus "necesidades personales" (Tebboth, 1938:42), la escuela de adultas y las reuniones de rezo tenían por misión domesticar y maternizar a las mujeres mayores, desacreditando e infantilizando la lógica que subyacía al conjunto de sus representaciones y prácticas. Además, mediante estos nuevos espacios de socialización se buscaba predisponer a las mujeres hacia nuevas actitudes, como el diálogo y la "conversación", buscando contrarrestar la "timidez" femenina que a los misioneros se les figuraba hostil y hermética. 
Mariana Daniela Gómez

\section{Reflexiones finales: la indiferencia como estrategia de resistencia}

Hay una serie de factores que permiten comprender la exigua convocatoria que las actividades de la misión tenían para las mujeres. Por un lado, la temporalidad y espacialidad que imponía la misión se mostraba contradictoria con los ritmos del ciclo doméstico femenino. Hasta 1910, los primeros misioneros anglicanos seguían a los nativos en sus circuitos de caza, pesca y recolección (Torres Fernández, 2007), pero cuando se abrió la Misión El toba esta pauta ya no formaba parte de su política, la cual, por diversas razones (entre las principales está el hecho de que no contaban con un financiamiento regular para cubrir la alimentación de las poblaciones) nunca prohibió que los indígenas mantuviesen una movilidad - más limitada - para la búsqueda de recursos montaraces. Durante las década del 1930 y de 1940 las mujeres se internaban en el monte por días o semanas con el fin de recolectar diversas variedades de frutos. Sus aportes eran fundamentales para la economía de las familias y ante la austeridad del financiamiento anglicano, los alimentos traídos y procesados por ellas no se podían despreciar.

Otro punto crucial es la actitud de franca indiferencia que las mujeres mostraban frente a la intromisión misionera en sus vidas. Una ofensiva directa contra los misioneros era improbable, si consideramos que fueron sus maridos y padres quienes interpelaron a los misioneros a fines de la década de 1920 para que abrieran una misión en el territorio toba. Así, las resistencias femeninas activas pero silenciosas eran las que estaban a la orden del día: la simple indiferencia ante los nuevos preceptos morales y religiosos y la reanudación de sus actividades cotidianas como si nada nuevo ocurriese, eran actitudes comunes en las mujeres.

La estrategia de la indiferencia seguramente les permitiría tener un mayor control sobre el proceso de invasión cultural y conversión religiosa. Por su parte, los misioneros, debido a su lectura y sesgo cultural sobre la naturaleza de las mujeres (como 
¿Morirán mis hijos o las frutas del monte se secarán si no canto y uso mi amuleto cada noche?

seres no poderosos) no vieron en ellas sino "timidez", cuando en verdad y paradójicamente la cotidianeidad de las aldeas del Chaco les revelaba que las cualidades más sobresalientes de éstas y otras indígenas eran la fortaleza y la vigorosidad corporal para la recolección en el monte, la agresión inter-femenina y la reclusión frente a la polución de sus peligrosos cuerpos y fluidos, características más bien contrarias a la "timidez". Por ello, la timidez parece ser un diacrítico atribuido por la mirada occidental y masculina de la época. Una hipótesis que surge entonces es que esta actitud tímida y silenciosa era en verdad un comportamiento estratégico que fomentaba el no-diálogo y la indiferencia de las mujeres hacia los extraños. Las mujeres podían mostrarse tímidas (en verdad cautas, precavidas, distanciadas) para evitar lidiar o acomodarse a las nuevas pautas que se estaban instaurando en la misión.

Debemos agregar que la escasa intervención de los misioneros en los hogares de los tobas durante las primeras dos décadas seguramente coadyuvó a que las mujeres continuaran reproduciendo ciertas esferas femeninas de acción que, si bien eran marginales a la dinámica hegemónica del liderazgo masculino - del viejo y del embrionario liderazgo religioso nativo , representaban espacios donde ejercían el poder y la autoridad a niveles inter-femeninos. También continuaron reproduciendo un conjunto de prácticas centrales en la construcción del habitus femenino, como los rituales y la relación con el monte y sus recursos. En suma: la invisibilización y la marginalidad del poder femenino colaboraron con su propio resguardo ya que una serie de roles y rituales femeninos no fueron vistos como las teclas del poder indígena. Los misioneros se concentraron en asestar $y$ desconstruir la praxis masculina. Las mujeres, en el mejor de los casos, sólo representaban un influjo nocivo para los maridos ganados a la fe cristiana.

En relación a lo anterior, hay que considerar que los misioneros no les ofrecieron ningún espacio de poder a las mujeres en la nueva estructura social y de liderazgo que 
procuraron construir, a pesar, por ejemplo, de que entre las primeras catorce personas convertidas en 1936 se encontraban tres mujeres (y con el tiempo se convertirían varias más). Algunas mujeres se convertían junto a sus maridos o recibían alguna señal divina que auguraba su futura conversión y los deseos de transformarse en una cristiana, casos que nos indican que existían una variedad de interacciones entre las mujeres y la misión, más allá de la indiferencia y la resistencia. Sin embargo, es claro que a diferencia de lo que sucedió en otros contextos coloniales de encuentro entre indígenas y misioneros (Sleeper-Smith, 2001), las mujeres no adoptaron las actividades de la misión para "escapar" de ciertos roles tradicionales impuestos por su cultura.

$\mathrm{Si}$ se leen con atención los informes de los misioneros, se observa que los aspectos positivos que se rescatan de la cultura toba, y de los indígenas chaqueños en general, suelen estar encarnados en actividades masculinas, fundamentalmente en aquellas que se le presentan como más heroicas al imaginario occidental. El hombre toba si bien carece de "inteligencia", de "claridez espiritual" y de "razón", al menos guarda cierto dominio heroico del monte, forjado durante siglos en una estrecha relación con la naturaleza. Pero el alter ego femenino de este sujeto carece de exotismo, de heroísmo y conlleva una alteridad más radical que la masculina. Las actividades de las mujeres y su aspecto físico escandalizaban por su "inversión" y aunque llamaban la atención momentáneamente, eran de menor interés para el proceso de conversión que deseaban los misioneros, quienes asumían que el portavoz del cambio cultural y espiritual debían ser los hombres, no las mujeres.

Así, el hecho de que los misioneros anglicanos, a pesar de contar con mujeres en sus filas, no hayan vislumbrado a las tobas como depositarias de los roles ofrecidos a los hombres, tiene que ver, seguramente, con la visión androcéntrica que traían de su país de origen. Empero es probable que dicha lectura haya tenido líneas de conexión con la ideología y el simbolismo de género de los grupos tobas. Aquí el sujeto marcado para ostentar 
¿Morirán mis hijos o las frutas del monte se secarán si no canto y uso mi amuleto cada noche?

conocimiento, una oratoria especial y ejercer poder $e$ influencia en niveles que superaban a la familia extensa usualmente fue (y todavía es) masculino. Por ello es probable que el proceso de misionalización anglicana haya venido a reforzar esta orientación hacia el exterior que histórica y culturalmente detentaban los hombres indígenas del Chaco. No obstante, y como he señalado en mi investigación (Gómez, 2011), en los grupos de ascendencia guaycurú tanto los hombres como las mujeres utilizaban la agresión física en diferentes direcciones para defender sus intereses. En el primer caso, dirigida hacia el exterior o hacia los miembros de los exogrupos; en el segundo, como se puede deducir del análisis de las peleas de mujeres, hacia el interior, es decir, hacia las mujeres tobas de otros grupos domésticos que amenazaban el control económico y sexual de los hombres que formaban parte de las unidades domésticas.

Además, en otra dimensión, las mujeres eran consideradas poderosas y peligrosas debido a sus fluidos corporales; sin embargo condensaban un poder desbordante sobre el cual se ejercía control social, tarea que solía estar a cargo de las mujeres mayores. Existían mujeres hechiceras (conanagae) y temidas por su poder letal de muerte, pero el hecho de que no hayan sido perseguidas y de que casi no sean mencionadas como una amenaza para la acción misionera, revela que el rol de la conanagae era marginal y acotado (aunque temido) comparado con el que detentaba el chamán.

Finalmente, cabe preguntarse cómo es que finalmente ha calado el proceso de conversión religiosa en la vida de las mujeres tobas - a pesar de las resistencias desplegadas durante las primeras dos décadas -, pues en la actualidad todas ellas muestran una sólida adscripción a la religión protestante (anglicana y posteriormente pentecostal). La apropiación que han hecho las mujeres del discurso religioso que se observa actualmente en las comunidades, así como la pérdida de autonomía individual en dimensiones como la sexualidad y el control de la natalidad, indican que los misioneros intervinieron 
finalmente en la regulación de la vida sexual, reproductiva y afectiva, a pesar de que esto no se mencione en las fuentes.

\section{Referências bibliográficas}

BouRdieU, Pierre. El Sentido Práctico. Taurus, Madrid, 1991.

BRANGDON, Kathleen. Gender as a social category in Native Southern New England. Ethnohistory 43(4), 1996, pp.573-594.

BRAUNSTEIN, José. Algunos rasgos de la organización social de los indígenas del Gran Chaco. Trabajos de Etnología. n ${ }^{\circ} 2$, Instituto de Ciencias Antropológicas, Universidad de Buenos Aires, 1983, pp.13107.

Citro, Silvia. Cuerpos significantes. Travesías de una etnografía dialéctica. Buenos Aires, Biblos, 2009.

CHÁVEZ, Jaime Flores y AVENDAÑO, Alonso. Fotografía de capuchinos y anglicanos a principios del siglo XX: la escuela como instrumento de cristianización y chileanización. Memoria Americana 14, 2006, pp.7587.

DE LA CRUZ, Luis María. Apuntes para la reconstrucción historiográfica de las iglesias no católicas en el Gran Chaco. Actas de las Jornadas de Geohistoria Regional X, 1989, pp.70-84.

FonTANA, Luis Jorge. El Gran Chaco. Solar/Hachette, Buenos Aires, 1977.

FouCAUlt, Michel. Seguridad, Territorio y población. Buenos Aires, Fondo de Cultura Económica, 2006.

. Vigilar y Castigar. Nacimiento de la prisión. Buenos Aires, Siglo XXI, 2008.

GóMEZ, Mariana. Las mujeres en el monte: las formas de vinculación con el monte que practican las mujeres tobas (qom). Revista Colombiana de Antropología, vol. 44 (2), 2008, pp.373-408.

- Percepciones e imágenes de las mujeres tobas sobre los proyectos de desarrollo artesanal en sus comunidades. VIII Reunión de Antropología del MERCOSUR, Buenos Aires, 2009a. 
¿Morirán mis hijos o las frutas del monte se secarán si no canto y uso mi amuleto cada noche?

306.

. El género en el cuerpo. Revista AVA 15, 2009b, pp.289-

¿Bestias de carga? Fortaleza y laboriosidad femenina para el capital. La incorporación de las mujeres indígenas al trabajo en los ingenios. En: CITRO, Silvia. (comp.) Cuerpos Plurales. Ensayos antropológicos de y desde los cuerpos. Buenos Aires, Biblos, 2010 (En prensa).

- De Recolectoras a Artesanas: Género, Identidades y Espacialidades entre las mujeres tobas. Tesis de Doctorado. Facultad de Filosofía y Letras, Universidad de Buenos Aires, 2011.

GoRDILLO, Gastón. Landscapes of devils. Tensions of places and memory in the Argentinean Chaco. Durhan, Duke University Press, 2004.

HARBIN, Michael y SERGEI, Kan. Introduction. Ethnohistory, 43(4), 1996, pp.563-571.

LAGOS, Marcelo. La cuestión indígena en el Estado y la sociedad nacional. Gran Chaco 1870-1920. Jujuy, Universidad Nacional de Jujuy, 2000.

MENDOZA, Marcela. Western Toba Messianism and Resistance to Colonization, 1915-1918. Ethnohistory, 51(2), 2004, pp.293-316.

MÉTRAUX, Alfred. Studies of Toba-Pilagá Ethnography (Gran Chaco). New Haven, Human Relations Area Files, 1980.

. La mujer en la vida social y religiosa de los indios Chiriguanos. Reseña y trabajos científicos del XXVI Congreso Internacional de Americanistas, Sevil, 1945, Tomo I, Madrid, 1948, pp.416-430.

NiKLISON, José Elías. Los tobas. Jujuy, Universidad Nacional de Jujuy, 1990 [1916].

NOTARIANNI, Dianne. Making Mennonites: Hopi Gender roles and Chrhistian transformations. Ethnohistory 43(4), 1996, pp.593-612.

SLEEPER-SMITH, Susan. Indian women and French men: rethinking cultural encounter in the Western Great-Lakes. Massachusetts, University of Massachusetts Press, 2001. 
STORM, Olaf. El río Pilcomayo y el Chaco Boreal. Viajes y Exploraciones. Buenos Aires, Compañía Sud Americana de Billetes de Banco, 1892.

TORRES FernándeZ, Patricia. Proyectos, Discursos y Políticas Misionales en el Chaco Centro-Occidental durante la primera mitad del siglo XX. Tesis de licenciatura, Facultad de Filosofía y Letras, Universidad de Buenos Aires, 2006.

. Políticas Misionales anglicanas en el Chaco CentroOccidental a principios del siglo XX: entre comunidades e identidades diversas. Población y Sociedad. Revista Regional de Estudios Sociales 14/15, Universidad Nacional de Tucumán, 2007, pp.139-176.

WrIGHT, Pablo. Presencia protestante entre aborígenes del Chaco argentino. Scripta Ethnologica VIII (7), 1983, pp.73-84.

\section{Fuentes utilizadas}

ARNOTT, John. A tour among the Toba villages. South American Missionary Society Magazine, vol. LXVI, 1933, pp.42-43.

Mision Pilaga. Autom. South American Missionary Society Magazine, vol. LXXII, 1938, pp.135-137.

Fox, Harold. The curse of the Canefields. South American Missionary Society Magazine, XCII (939), 1958, p.24.

Hunt, J. A Toba chief comes in. South American Missionary Society Magazine, vol. LXII, 1928.

LEAKE, Alfred. The Toba Misión Staff Notes. South American Missionary Society Magazine, vol. LXV, ${ }^{\circ}$ 7301931, p.52.

. Progress in Toba Mission. South American Missionary Society Magazine, vol. LXVII, 1933a.

. The Store of the Toba Mission. South American Missionary Society Magazine, vol. LXVII, 1933b.

. A chief dies. South American Missionary Society Magazine, vol. LXXVII (849), 1943, pp.11-12. 
¿Morirán mis hijos o las frutas del monte se secarán si no canto y uso mi amuleto cada noche?

Twenty one years old. South American Missionary Society Magazine, vol. LXXXII (833), 1948, pp.63-64.

LEAKE, Olivia. Toba Mission Staff Notes. South American Missionary Society Magazine, vol. LXVI, n 745, 1932.

Misión El toba. South American Missionary Society Magazine, vol. LXVIII, $n^{\circ}$ 770, 1934.

PRICE. J. On the banks of the pilcomayo River. South American Missionary Society Magazine, vol. LXXI, 1937, p.56.

SMITH, Colin. A Message from the Argentine Chaco. The people want a Mission. South American Missionary Society Magazine, vol. LXIII (703), 1929a, p.22.

Continued appeals from the tobas of Argentin". South American Missionary Society Magazine, vol. LXIII (795), 1929b, p.43.

TЕввотH, Thomas. Misión 'El toba'. Report for Quarter Ending, 1937. South American Missionary Society Magazine, vol. LXXII, 1938, pp.41-42.

. Misión El toba. South American Missionary Society Magazine, vol. LXXXVI (843), 1942, p.14.

- Misión El toba. South American Missionary Society Magazine, vol. LXXVII (849), 1943, pp.36-37.

TеввотH, Dora. With Teb. Among the Tobas. The Lantern Press an Imprint of Churchman Publishing Limited, 1989. 